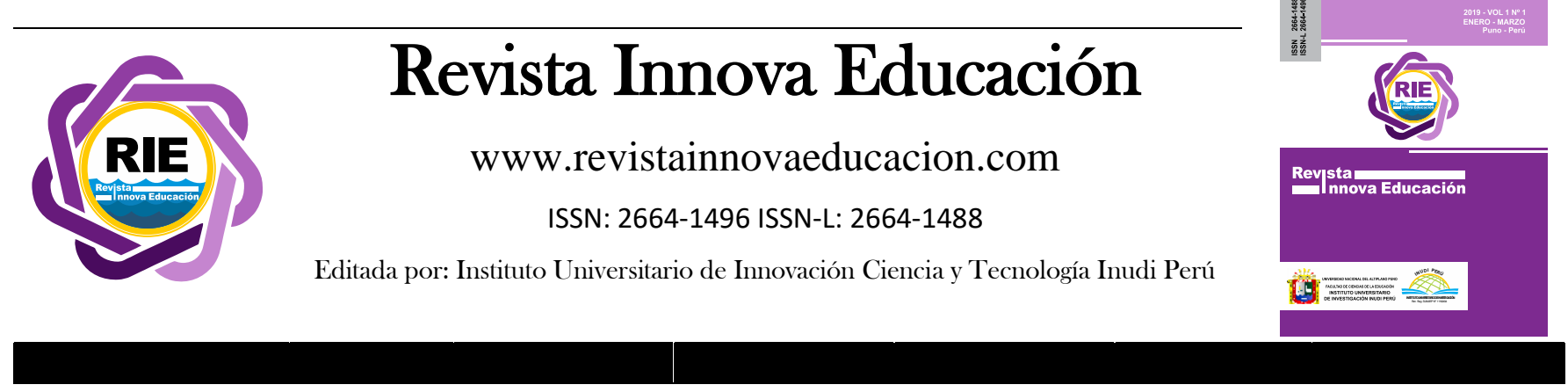

\title{
El significado del poema "Manicomio" de Alberto Mostajo desde la perspectiva del análisis del discurso poético
}

\author{
The meaning of the poem "Manicomio" by Alberto Mostajo from the perspective of the analysis \\ of poetic discourse
}

\author{
Tania Choquepata (D); Dina Mamani-Aro \\ DOI ${ }^{\prime}$ https://doi.org/10.35622/j.rie.2019.03.007
}

Universidad Nacional del Altiplano, Perú

Facultad de Ciencias de la Educación

Programa Académico de Lengua, literatura, psicología y filosofía

Recibido el 15/07/2019/ Aceptado el 24/07/2019

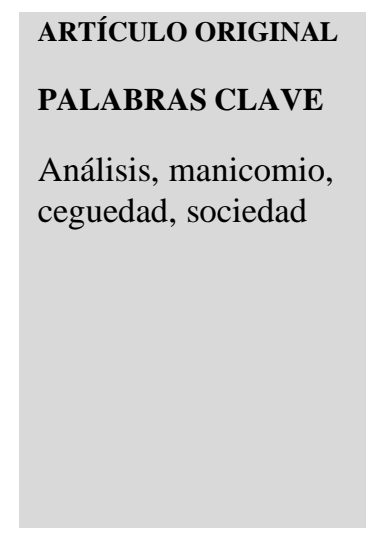

KEYWORDS

Analysis, madhouse, blindness, society
El objetivo fue analizar e interpretar el significado del poema "Manicomio" de Alberto Mostajo desde la perspectiva del análisis del discurso poético. El método de investigación que se aplicó fue la hermenéutica y la técnica fue el análisis del discurso, por el cual se consideró las siguientes dimensiones: textual, semiótica, enunciativa y pragmática. El poema Manicomio es una construcción lingüística que cumple con los criterios de textualidad. A nivel semiótico, el poema nos da a entender al mundo como Manicomio por la nostalgia, la tristeza profunda que siente el autor al ver la ceguedad y la inconciencia de la personas frente a los problemas de la sociedad. A nivel enunciativo, Mostajo expresa en primera persona a través del sujeto lírico que observa cómo la sociedad es indiferente a los hechos o sucesos que los rodea, y se centran en los placeres de la vida. A nivel pragmático, el sujeto lirico cumple con transmitir ideas al lector u oyente con la intención de generar la reflexión y la toma de conciencia.

The objective was to analyze and interpret the meaning of the poem "Manicomio" by Alberto Mostajo from the perspective of the analysis of poetic discourse. The research method applied was hermeneutics and the technique was discourse analysis, by which the following dimensions were considered: textual, semiotic, enunciative and pragmatic. The Asylum poem is a linguistic construction that meets the criteria of textuality. At a semiotic level, the poem gives us to understand the world as an Asylum for nostalgia, the deep sadness that the author feels when he sees the blindness and the unconsciousness of people facing the problems of society. At the enunciative level, Mostajo expresses in the first person through the lyrical subject who observes how society is indifferent to the events or events that surround them, and focus on the pleasures of life. At the pragmatic level, the lyrical subject fulfills transmitting ideas to the reader or listener with the intention of generating reflection and awareness. 


\section{INTRODUCCIÓN}

El manicomio es definido en el diccionario como un establecimiento donde se cuida a los enfermos mentales (Gran diccionario de la lengua española, 2016) por lo que nos referimos a personas que fueron separadas de la sociedad y encerradas junto con otras personas con el mismo problema, y cada uno de ellos es ajena a su realidad.

En un aspecto filosófico el manicomio es considerado como un instrumento del Estado establecido para silenciar a quienes, con su manera de pensar, sentir o comportarse, cuestionaban o amenazaban los valores de las clases dominantes (Foucault, 2015; Sacristán, 2009).

Basaglia (1978) manifiesta que en nuestra sociedad capitalista los hombres viven, enferman, son asistidos y mueren de clase. La enfermedad y la locura son, desde luego, contingencias a las que está expuesto por su doble condición de ser vivo y de sujeto de deseo, el habla y la angustia de todo ser humano. Pero ¿Cómo?, ¿Cuándo?, en que forma y bajo qué condiciones sociales perderá su salud o su razón y la asistencia que recibirá en uno u otro trance, dependerán decisivamente de su condición de clase. Por lo que el manicomio es una institución donde la sociedad aísla a aquellas personas que consideran diferentes, el estado usa estas instituciones para controlar la marginalidad social, es decir, encerrar a la clase obrera que no genera ganancia al estado (Basaglia, 2008; Prieto, 2016).

Bevir (2011) muestra que los científicos de las Ciencias Humanas deberían apelar al inconsciente solo cuando el lenguaje de lo consciente les falla, esto es, especialmente cuando encuentran un conflicto entre la autocomprensión de las personas y sus acciones. Este estudio muestra también que los científicos de las Ciencias Humanas deberían adoptar un concepto más amplio de lo inconsciente que aquel desarrollado por Freud, es decir, un concepto que esté libre de la concepción freudiana histórica de los instintos y su énfasis histórico en las experiencias sexuales de la niñez. Lo inconsciente, entendido de esta manera, tiene una relación ambigua con las más recientes vertientes lingüísticas y narrativas del Psicoanálisis.

"El mundo es un manicomio administrado por sus propios pacientes” (Vázquez, 2015). Vivimos en una sociedad segada, ignorando todo los problemas que nos rodean, donde cada persona se aísla y vive el mundo que quiere vivir sin importarle lo demás (García, 2015).

Cardozo (2016) nos habla de la "normopatía" una enfermedad frecuente descrita por la corriente de la salud mental llamada "antipsiquiatría". Las personas portadoras de esta enfermedad viven sin cuestionar la sociedad en la que viven, aceptan las normas preestablecidas por esta de forma acrítica y pasiva. En un mundo capitalista, enfermo, que mata por guerras o por hambre a gran parte de la población, en un mundo que aliena, que violenta, que segrega, en el que el $1 \%$ de la población tiene la misma riqueza que resto del 99\%; el que acepta esto de forma acrítica. 
En el poema de Alberto Mostajo se aprecia el término manicomio que causa curiosidad. Alberto Mostajo fue un poeta dedicado a escribir, estudiaba los problemas humanos, no tenía ambiciones sino la de llevar una vida de poeta, se recluía en su habitación llena de libros. Se dedicó completamente a leer y escribir (Núñez, 2019).

Los poemas de Alberto Mostajo fueron estudiados desde diferentes perspectivas, sin embargo, no se evidencia ningún tipo de investigación sobre su poema "Manicomio". Por lo cual, se plantea como objetivo interpretar el significado del poema "Manicomio de Alberto Mostajo desde la perspectiva del análisis del discurso poético.

\section{MÉTODO}

La investigación corresponde básicamente al enfoque cualitativo; al respecto Sampieri, Fernández, \& Baptista (2006) nos habla de descubrir o interpretar la realidad subjetiva, en este caso la realidad de nuestro poema; interpretarlo desde nuestra propia perspectiva y así llegarlo a conocer de manera profunda. Asimismo, el enfoque cualitativo puede concebirse como un conjunto de prácticas interpretativas que hacen al mundo "visible", lo transforman y convierten en una serie de representaciones en forma de observaciones, anotaciones, grabaciones y documentos (Hernández, Fernández, \& Baptista, 2014). Por lo tanto, se aplicó la hermenéutica como método de estudio.

El método hermenéutico es multimetódico, naturalista e interpretativo, con la indagación de situaciones naturales en el contexto social, a fin de interpretar los fenómenos en términos de los significados que las personas les otorgan (Ybelisse, 2012). Es decir, estudiar los fenómenos dándole nuestro propio significado según lo que observamos y analizamos a través de un estudio detallado. Además, la hermenéutica se interesa por la necesidad de comprender el significado de los fenómenos y no solamente de explicarlos en términos de casualidad (Monje Álvarez, 2011).

Esta investigación se estableció bajo las posturas de la corriente fenomenológica para Lambert (2006) la fenomenología es entendida como análisis descriptivo de vivencias intencionales las cuales son observables; donde se da la utilización de la eidética y la heurística. La fenomenología también objeta la ruptura positivista entre el sujeto y el objeto reconociendo la interdependencia de ambos en el proceso del conocimiento (Monje Álvarez, 2011). Asimismo, el estudio se fundamenta basándose en Heidegger (2006); Husserl (1992) y Sartre (2006) quienes sostienen sobre la corriente existencialista, de la misma forma. Se aplica también para la mejor comprensión la postura del estructuralismo, en la dimensión antropológica y lingüística considerado por Chomsky (1999) y Harris (2004).

\subsection{EL DISCURSO POÉTICO}

En el objeto de estudio, se empleó la técnica de análisis del discurso poético para analizar los resultados correspondientes, para Correa (2012) un discurso es concebida como una cualidad de las personas para desarrollar ideas a partir de cúmulo de significados y signos que se asocia con la 
transmisión de un mensaje oral u escrito. El poema es un producto discursivo con una construcción lingüística dotada de sentido, por lo tanto, el discurso poético no representa a una realidad, más bien la construye con elementos identificables en el contexto real, es decir, crea nuevas realidades a través del lenguaje. No imita sucesos o acciones reales, sino un acto verbal. Dicho de otro modo, el poema es un discurso ficticio que imita el discurso real (Núñez, 2019). Por lo tanto, un poema no es un suceso ni solo una representación ficticia fijada en forma escrita. Un poema es un discurso imitado a través de gestos (Calles, 1997).

En el objeto de estudio, se empleó la técnica de análisis del discurso poético para analizar los resultados correspondientes, basada en los presupuestos teóricos explícitos de Van Dijk (1992) y como modelo de interpretación literaria se tomó en cuenta las propuestas de, la cual consta de cuatro dimensiones: textual, enunciativa, semiótica y pragmática.

A continuación, se da a conocer cada una de ellas.

\section{a) Dimensión textual}

Según Satriano \& Moscoloni (2000) se refiere principalmente a las propiedades textuales y que el texto acude a la sintaxis y a la semántica, donde la sintaxis describe categorías como sustantivos que aparecen en las oraciones, incluyendo las combinaciones posibles y las formas más globales del discurso, mientras tanto, la semántica, se encarga de los significados de las palabras, de las oraciones y hasta del discurso.

Por otra parte, Caruman \& Quiroga (1960) nos dicen que el texto es un concepto abstracto que se concreta a través de distintos discursos y su estudio debe ser abordado interdisciplinariamente desde la lingüística, la socio-lingüística, la psicolingüística, la teoría de la comunicación.

Para, Van Dijk (1998) el texto es una construcción teórica propia e independiente que normalmente se denomina discurso, de tal forma es considerado como un hecho comunicativo y como tal constituido por un canal de comunicación y por las acciones del lenguaje que actualizan este canal. Lo que sucede es que los lectores se relacionan no con el texto aislado, sino con un soporte o portador de texto.

Mientras que, afirma que la dimensión textual, es una categoría que permite explicar la textura del discurso poético, es decir, el soporte textual. En esta dimensión, el poema se estructura en función de unidades textuales, tales como los enunciados o las estrofas; para que un poema sea considerado como texto. Para lo cual se realizan el análisis de los mecanismos de cohesión y el análisis de la coherencia.

Por último, Penas \& González (2009) manifiestan que la dimensión textual es el medio por la cual se lleva a cabo la comunicación y que responden a una unidad lingüística del texto. Y las autoras nos dan a conocer que la lingüística del texto es una innovación radical no solo de los 
estudios lingüísticos, sino que también se aplica en los estudios literarios, al proporcionar los fundamentos y líneas generales para establecer modelos de análisis de textos.

\section{b) Dimensión enunciativa}

Para Pico (2009) es el acto de enunciar, de manifestar, es la aparición del texto, aquello que es mostrado y que, al ser visto, pasa a ser objeto de diálogo e interpretaciones en los grupos sociales. Mientras que para Cabo \& Gullón (1998) la dimensión enunciativa se ahonda en las implicaciones del hecho comunicativo, en tanto se indaga, a través de los enunciados que conforman el texto, por su relación con quiénes participan en la situación de comunicación enunciadores, los propósitos que se persiguen de acuerdo con una audiencia específica podría decirse que en esta dimensión, a diferencia de las anteriores, se avanza en la profundidad del texto.

Según Filinich (2011) Un enunciado conlleva dos niveles, de los cuales uno es explicito, lo enunciado, aquello que es objeto del discurso; y el otro, implícito, la enunciación, presupuesta por todo enunciado en la medida en que todo discurso proviene de un yo que destina su alocución a un tú. Desde esta perspectiva la dimensión enunciativa se compone de sujeto, verbo y objeto, siendo el sujeto de la enunciación el yo-tú, el verbo de la enunciación aquel que designa el acto enunciativo y el objeto de la enunciación, el propio enunciado.

Para Cabello (2015) manifiesta que en la dimensión enunciativa es la actitud que describe e influye en el lector a partir de la forma en que se usa el lenguaje para contar hechos, datos, ideas, emociones o creencias, y especialmente a partir del énfasis de sus juicios sobre certidumbre, importancia, confianza, etc.

Por lado, Núñez (2019) menciona que esta dimensión permite reconocer las distintas voces que intervienen en el discurso poético. A la vez, permite describir los rastros que dejan los creadores del discurso en sus enunciados. Se basa en la teoría de la enunciación. Se realiza los procesos de identificación del sujeto lirico y sujeto empírico y la explicación del punto de vista del hablante, la imagen que proyecta de si y el enunciatario.

\section{c) Dimensión semiótica}

Correa (2012) nos dice que el análisis semiótico permite descomponer un discurso, un texto y encontrar sus elementos básicos y los significados individuales de cada elemento e identificar las relaciones que se originan a través de la mezcla de diferentes signos, símbolos, señales o íconos. De los elementos básicos del que nos habla Correa son los lexemas y semas que componen al discurso poético, a través del cual podemos interpretar la poesía "Manicomio".

Para Niño (2007) la semiótica como disciplina que estudia los signos en el seno de la vida social y, en un ámbito más particular, la lingüística como la ciencia de las leyes y principios que rigen las lenguas naturales, han prestado servicios valiosos en los avances del conocimiento en 
dirección de la comprensión de lo típicamente humano. Como símbolo, hace posible la representación mental de las cosas y fenómenos; como síntoma, le facilita al ser humano proyectarse, expresarse, crear desde su interioridad; y como señal, le permite interactuar con los demás, producir y compartir la cultura. Símbolos, síntomas y señales equivalen a los signos del lenguaje.

Por otro lado, Tobón (2004) sostiene que en la semiótica constituyen tres dimensiones: la pragmática, la sintaxis y la semántica, estas tres dimensiones se entienden en la medida en que obedecen a determinadas reglas cuyos antecedentes se remontan en la retórica. De esta manera, la semiótica estudia las relaciones de los signos con los objetos a los cuales son aplicables. El objeto de estudio puede ser también la relación de los signos con los intérpretes.

Para Molina (2006) la semiótica consiste en una unidad comunicativa, incluido su valor pragmático, como un signo dentro de un sistema de signos, lo que permite esta dimensión es localizar un mensaje dado en el marco de un sistema general de valores apropiado a una cultura dada. La noción de contexto la semiótica se relaciona con la interacción e intertextualidad. También es la que permite abordar tres dimensiones: la interacción comunicativa, pragmática y semiótica las cuales son interdependientes.

Según Núñez (2019) esta categoría semiótica permite determinar el sentido y significado del poema, teniendo en cuenta que todo lo que el hombre hace y piensa tiene significado. Núñez (2019) se basa en la teoría semiótica, en esta categoría se realiza la determinación de semas, de los lexemas más importantes del poema, combinación de semas identificados, explicación de la isotopía que son los semas reiterativos y la fijación del sentido y la significación del poema.

\section{d) Dimensión pragmática}

Según Lada (2001) la pragmática supone un acercamiento dinámico al estudio del signo literario, por cuanto tiene en cuenta las variantes de uso que están presentes en los procesos concretos de comunicación, superando de este modo tanto los métodos extrínsecos como los métodos inmanentistas de investigación del discurso literario. En la pragmática se debe considerar los actos del habla y el contexto. Cuando hablamos de actos del habla nos referimos a una acción de un lenguaje, por ejemplo: ordenar. En tal sentido, se conocen tres tipos de actos de habla, las cuales, son: primero, elocutivos (intención del hablante) segundo, locutivos (portadores de significado) y tercero, perlocutivos (efectos que producen en el receptor). Cuando hablamos de contexto nos referimos a todos los factores que condicionan la interpretación del discurso, entre ellas tenemos el espacio, el tiempo, también incluyen los factores sociales y culturales relacionados con los interlocutores.

Según Reyes (1995) sostiene que la pragmática es una subdisciplina lingüística, y su objeto es el significado del lenguaje en uso. La pragmática es entendida, de metáforas que sugieren un cambio de enfoque en el estudio del significado, el que desborda a la semántica. A partir de eso la 
pragmática nos permite construir enunciados, es decir textos que son partes de redes de textos y nos permite interpretar los enunciados ajenos.

Para Núñez (2019) la dimensión pragmática permite explicar el contexto en que fue escrito el poema y el contexto en que el lector recibe o lee el poema. También ayuda a precisar la intención comunicativa del emisor, es decir, describir el acto ilocutivo. Del mismo modo, permite determinar las sensaciones y emociones que produce el poema en los lectores.

\subsection{CORPUS DE ESTUDIO}

\section{POEMA MANICOMIO}

\section{I}

Ríe el mundo en los contornos.

Policromía danzante

de bultos y máscaras eléctricas.

Cuatro llaveros pensantes

en las esquinas de la sala de consulta.

Volcanes que se agitan;

esfinges que lloran.

Entre pasillos, ronda la Ciencia

auscultando tumbas dormidas.

Afuera, en ondas musicales, trajina el lujo y la miseria.

Siembra de negaciones;

relámpagos de axiomas.

Espiral teñida de sombras

en la cita de un eterno crisol.

Masticando su propio sueño

marchan todos al mismo teorema.

\section{II}

Himnos de sangre.

Nervios de piedra.

Un huracán de tristeza

azota la soledad de la estancia.

Pesadilla de sueños

frente a los ojos brujos

de una lámpara centinela.

En la curva del reloj adormecido 
danzan suspiros de la noche.

Tragedias de olvido.

Telarañas de recuerdo.

Cascadas de gritos mendigos

sobre la acústica analítica

del pabellón solitario.

Diabólica simetría ambulante.

Acá y allá, fantasmas burlones

juegan a dados con la muerte.

Giran las pupilas, paralelas

adivinas del enigma de las cosas.

\section{ANÁLISIS E INTERPRETACIÓN DE RESULTADOS}

\subsection{DIMENSIÓN TEXTUAL:}

En el poema "Manicomio" se aprecian dos estrofas, la primera con tres enunciados; la segunda estrofa con tres enunciados, haciendo un total de 6 enunciados las cuales se muestran en la Tabla 1 , que en su conjunto forman la textura discursiva.

Tabla 1 Enunciados del poema "Manicomio"

1. Ríe el mundo en los contornos. /Policromía danzante de bultos y máscaras eléctricas. /Cuatro llaveros pensantes /en las esquinas de la sala de consulta.

2. Volcanes que se agitan; lesfinges que lloran. /Entre pasillos, ronda la Ciencia/auscultando tumbas dormidas.

3. Afuera, en ondas musicales, /trajina el lujo y la miseria. /Siembra de negaciones; /relámpagos de axiomas. /Espiral teñida de sombras/en la cita de un eterno crisol. IMasticando su propio sueño/marchan todos al mismo teorema.

4. Himno de sangre. /Nervios de piedra. /Un huracán de tristeza/azota la soledad de la estancia. /Pesadilla de sueños/frente a los ojos brujos/de una lámpara centinela. /En la curva del reloj adormecido/danzan suspiros de la noche.

5. Tragedias de olvido. Thelarañas de recuerdo. /Cascadas de gritos mendigos/sobre la acústica analítica/del pabellón solitario. /Diabólica simetría ambulante. /Acá y allá, fantasmas burlones/juegan a dados con la muerte.

6. Giran las pupilas, paralelas/adivinas del enigma de las cosas. 
En este análisis de la cohesión del texto se observan algunos elementos cohesivos. En el primer enunciado el elemento cohesivo conjunción "y", cumple la función de unir dos partes de una oración, la cual une "Policromía danzante de bultos" y "mascaras eléctricas" En el segundo enunciado tenemos la anáfora "que" la cual se repite al inicio de una oración, "Volcanes que se agitan" "esfinges que lloran". En el tercer enunciado también observamos una deixis, "afuera" que señala un lugar al discurso "afuera, en ondas musicales". Así mismo se aprecia una elipsis "trajina", "trajina el lujo y la miseria", se sobreentiende el verbo "trajina" que tiene. También se observa el mecanismo cohesivo repetición "sueño" que es la repetición de una o más palabras "masticando su propio "sueño"/ marchan junto al mismo teorema" y "pesadilla de sueños / frente a los ojos brujos". En el cuarto enunciado tenemos la progresión temática "huracán de tristeza" que se dosifica y organiza el desarrollo de la información del poema. Así también se observa el mecanismo cohesivo repetición "soledad" que es la repetición de una o más palabras "azota la soledad de la estancia" y "sobre la acústica analítica / del pabellón solitario". En el quinto enunciado observamos las deixis "acá" y "allá" que señalan un lugar "acá y allá fantasmas burlones". Y el sexto y último enunciado tenemos la coma vocativa “," que se usa para separar el vocativo y el mensaje, "giran las pupilas, paralelas".

También encontramos figuras literarias presentes en el poema "Manicomio", entre ellas tenemos la prosopopeya que es el procedimiento retórico que consiste en atribuir cualidades propias de un ser racional o animado a otro inanimado (Ríe el mundo en los contornos / Cuatro llaveros pensantes / Cascadas de gritos mendigos / Acá y allá, fantasmas burlones), encontramos también el epíteto que es el adjetivo que se emplea para atribuirle cualidades al sustantivo a que acompaña (máscaras eléctricas / tumbas dormidas / Espiral teñida /ojos brujos / reloj adormecido / pabellón solitario), luego tenemos la perífrasis que se denomina así a la cierta forma de expresarse dando rodeos o empleando más palabras de las que normalmente hubieran sido necesarias para comunicar una idea o concepto, al decir (Cuatro llaveros pensantes len las esquinas de la sala de consulta), hace referencia a los cuatro puntos cardinales de nuestro planeta. Encontramos también la sinécdoque es una figura literaria en la cual se denomina a una cosa por el nombre de otro en relaciones que pueden ser del todo por la parte (o viceversa), la especie por el género (o al revés) o el material por el nombre de la cosa (trajina el lujo y la miseria / Nervios de piedra), también tenemos el hipérbaton, es una figura literaria en la cual el orden convencional de las palabras en la oración es alterado por razones expresivas o, en el caso de la poesía, para ajustarlo a la métrica, el ritmo o la rima de la frase (Masticando su propio sueño / marchan todos al mismo teorema), luego tenemos la hipérbole, que tiene lugar cuando se aumenta o disminuye de manera exagerada un aspecto o característica de una cosa (Un huracán de tristeza) y por ultimo tenemos la metáfora que es la relación sutil de analogía o semejanza que se establece entre dos ideas o imágenes (Giran las pupilas, paralelas / adivinas del enigma de las cosas).

El siguiente análisis de la coherencia del texto se basa en la teoría de Beaugrande \& Dressler (1997). El concepto que funciona como centro de control textual es "Ríe el mundo en los contornos.". Este concepto es el núcleo del texto, alrededor suyo orbitan los conceptos 
secundarios, estableciendo relaciones de distinto tipo. El agente "Policromía danzante" se relacionan con el concepto de tipo percepción "de bultos y máscaras eléctricas.”, que a su vez guarda relación con el concepto de tipo acción "Cuatro llaveros pensantes" que es afectado por el concepto de tipo percepción "en las esquinas de la sala de consulta." Nos indica la acción de los agentes en un contexto determinado. En el proceso de "ríe el mundo" aparecen los conceptos de "Volcanes que se agitan", que es afectado con el concepto de tipo acción "esfinges que lloran." que es relacionan con el concepto de tipo percepción "Entre pasillos, ronda la Ciencia" que es afectado por el concepto de tipo acción "auscultando tumbas dormidas". El concepto "Afuera, en ondas musicales ", está afectada por los conceptos de tipo acción "trajina el lujo y la miseria", "Siembra de negaciones" y "relámpagos de axiomas", el concepto "Espiral teñida de sombras" $y$ "en la cita de un eterno crisol" ambos conceptos de tipo percepción son afectados por los conceptos de tipo acción "Masticando su propio sueño" y "marchan todos al mismo teorema". Aparecen los conceptos "Himno de sangre", "Nervios de piedra" y "Un huracán de tristeza" Nos indica una comparación entre los agentes, además de que son afectadas por el concepto de acción "azota la soledad de la estancia" los conceptos de tipo percepción "Pesadilla de sueños", "frente a los ojos brujos", "de una lámpara centinela" y "En la curva del reloj adormecido" son afectados por el concepto de tipo acción "danzan suspiros de la noche”. A continuación, aparecen los conceptos "Tragedias de olvido", "Telarañas de recuerdo", "Cascadas de gritos mendigos", "sobre la acústica analítica", "del pabellón solitario" y "Diabólica simetría ambulante" que son conceptos de tipo percepción, el concepto de tipo percepción "Acá y allá, fantasmas burlones” es afectado por el concepto de tipo acción "juegan a dados con la muerte”. Por último, aparece el concepto "Giran las pupilas, paralelas" que es un concepto de tipo percepción que está afectado por un concepto de tipo acción "adivinas del enigma de las cosas". El último verso trata de decirnos que a través de lo que observamos y percibimos tratamos de entender este mundo muchas veces de manera imprecisa.

\subsection{DIMENSIÓN SEMIÓTICA:}

Para iniciar, se analizarán los siguientes lexemas:

Tabla 2 Primer grupo de lexemas y semas del poema "Manicomio"

\begin{tabular}{ll}
\hline Lexemas & Semas que genera \\
\hline "mundo" & /global/, /población/, /sociedad/, /cosmos/. \\
"contorno" & /borde/, /alrededor/, /perímetro/. \\
"sala" & /ambiente/, /entorno/, /lugar/. \\
"pasillos" & /camino/, /ruta/, /estrecho/. \\
"volcanes" & /cerros/, /montañas/, /sierra/. \\
"estancia" & /habitación/, /lugar/, /cuarto/, /permanencia/.
\end{tabular}


En una primera aproximación se afirma que los lexemas "mundo", "contorno", "sala", "pasillos", "volcanes" y "estancia" generan la isotopía espacio: los cuales representan a los espacios del manicomio, entendiendo por esto que el sujeto lírico observa su alrededor e interpreta al mundo como un manicomio.

Tabla 3 Segundo grupo de lexemas y semas del poema "Manicomio".

\begin{tabular}{ll}
\hline lexemas & semas que generan \\
\hline "ríe" & /felicidad/, /locura/, /alegría/. \\
"lloran" & /tristeza/, /angustia/, /pena/, /dolor/. \\
"miseria" & /pobreza/, /necesidades/, /tristeza/. \\
"lujo" & /dinero/, /riqueza/, /poder/, / joyas/. \\
"sueños" & /aspiraciones/, /deseos/. \\
"azota" & /golpes/, /daño/, /dolor/. \\
"soledad" & /desierto/, /melancolía/. \\
"tragedia" & /desgracia/, /infortunio/. \\
"olvido" & /descuido/, /omisión/. \\
"pesadilla" & /angustia/, /ansiedad/, /miedo/, /horror/. \\
"muerte" & /fin/, /oscuridad/, /miedo/. \\
"recuerdo" & /pasado/, /anterior/. \\
"juegan" & /alegría/, /festejo/, /distracción/, /celebración/. \\
\hline
\end{tabular}

En este segundo bloque de lexemas; la oposición de lexemas se da de la siguiente forma:

"ríe" vs "llora"

"lujo" vs "miseria"

"sueños" vs "pesadillas"

"caricias" vs "azota"

"juegan" vs "soledad"

"felicidad" vs "tragedia"

"recuerdo" vs "olvido"

"vida" vs "muerte" 
Ahora bien, gracias al primer bloque de lexemas ("mundo", “contorno", "sala”, "pasillos", "volcanes", "estancia"), se afirma que el sujeto reconoce al mundo como un manicomio. Donde se desplaza de una emoción agradable a un punto ligada a la destrucción, es decir, desde la lucidez (conciencia) a la locura (inconsciencia), desde la alegría a la tristeza; en donde ve al mundo como un espacio donde existe paz, felicidad, pero a la vez encontramos las desgracias del ser humano. Otro nivel de lectura sería que el sujeto compara la sociedad, el mundo con un manicomio. En consecuencia, el poema produciría el sentido de que vivimos en una constante destrucción que tratamos de tapar, con cosas superficiales, la vida se ha convertido en una constante lucha por la supervivencia, obtener la buena vida a base tragedias, donde los que luchan por lo justo se convierte en hojas secas quedadas en el olvido.

Tabla 4 Tercer grupo de lexemas y semas del poema "Manicomio"

\begin{tabular}{ll}
\hline Lexemas & Semas que genera \\
\hline "bultos" & /estorbo/, /incomodidad/, /carga/. \\
"sangre" & /rojo/, /muerte/, /agonizar/. \\
"piedra" & /duro/, /firme/. \\
"huracán" & /viento/, /fuerza/, /destrozo/. \\
"telarañas" & /viejo/, /olvidado/. \\
"cascadas" & /ruido/, /agua/, /alboroto/. \\
"pupilas" & /visión/, /mirada/, /observar/.
\end{tabular}

Los lexemas: "bultos", “sangre”, “piedra”, "huracán”, "telarañas”, “cascadas”, "pupilas”, expresan la realidad que el sujeto lírico observa dentro de su contorno, son realidades que ocurren dentro de la sociedad, lo que implica la lucha por su verdad, por sus ideales, por sus sueños. Hacer entender dicha lucha siempre va acompañadas de dificultades y tragedias.

Tabla 5 Cuarto grupo de sintagmas y semas del poema "Manicomio"

\begin{tabular}{ll}
\hline Sintagma & Semas que genera \\
\hline "máscaras eléctricas" & /doble cara/, /movimiento/, /cambiante/, /inconstante/. \\
"cuatro llaveros pensantes" & /razón/, /ubicación/. \\
"tumbas dormidas" & /sepultura/, /fosa/, /cadáver/, /silencio/, /oscuridad/. \\
"ondas musicales" & /notas/, /canciones/, /música/, /alegría/, /melodía/. \\
\hline
\end{tabular}




\begin{tabular}{ll}
\hline "mismo teorema" & /único/,/verdad/, /comprobable/. \\
"lámpara centinela" & /luz/,/perseverancia/. \\
"reloj adormecido" & /inservible/,/detenido/, /quieto/. \\
"fantasmas burlones" & /pasado/, /ridículo/.
\end{tabular}

El sintagma "máscaras eléctricas", hace referencia a los seres humanos que están en un constante cambio, ya sea sobre sus ideales, sueños o sus creencias. En cuanto al sintagma "cuatro llaveros pensantes", se refiere a la ubicación del manicomio, interpretándolos como: los cuatro puntos cardinales de la tierra. "tumbas dormidas", se refiere a aquello que está enterrado y no puede emitir ninguna clase de señal. "ondas musicales", nos muestra la felicidad con la que percibimos el mundo, que nos genera tranquilidad. "mismo teorema", este sintagma hace referencia a única verdad, a una verdad que todos creen. "lámpara centinela", es aquello que está en constante vigilia, una luz que no dejará de brillar. "reloj adormecido", el reloj es un objeto que mide el tiempo, por lo tanto, este sintagma se refiere a un tiempo detenido, un tiempo que se quedó estático y el sintagma "fantasmas burlones", se refiere a que nuestro pasado, siempre se encuentra presente haciéndonos recuerdo de aquello que no queremos recordar.

\subsection{DIMENSIÓN ENUNCIATIVA:}

La voz que narra el poema "Manicomio" se encuentra en tercera persona gramatical, cuyo punto de vista es subjetivo. La voz que habla no necesariamente pertenece a Mostajo, más bien es una estrategia que él la utiliza. Lo que se quiere decir que el autor crea un personaje que observa su realidad. Sin embargo, puede decirse que las emociones, las percepciones, las reflexiones que se expresan en el poema formen parte de la vida de Mostajo. De ser así, se estaría hablando del desdoblamiento del autor, o sea, éste es representado en el texto por el sujeto lírico, a su imagen y semejanza. A esta afirmación corrobora la perspectiva en tercera persona gramatical en la que se enuncia el poema. En suma, en el poema habría dos voces: la del autor y la del hablante lírico (sujeto textual).

El autor Mostajo a través del sujeto lírico observa cómo la sociedad es indiferente a los hechos o sucesos que los rodea, y se centran en los placeres de la vida (Afuera, en ondas musicales, / trajina el lujo y la miseria/) crea un sujeto lírico asombrado por la ignorancia de la sociedad hacia la concepción del mundo, desde condición enunciada del poema. El autor se muestra subjetivo, reflexivo frente a su discurso y a la realidad que percibe. Se construye a sí mismo como alguien que reflexiona sobre la realidad del mundo en el que vivimos, el tiempo y el espacio.

¿Para quién enuncia el hablante lírico?, ¿a quién se dirige? En el poema El sujeto lírico adopta la voz en el poema en tercera persona; por lo que no existe un destinatario, sino, existe un destinatario referencial externo del universo del poema.

\subsection{DIMENSIÓN PRAGMÁTICA:}

\subsubsection{Factores que condicionaron la producción del poema "MANICOMIO"}


El contexto en que se escribe el poema "Manicomio" El autor Alberto Mostajo (Piel de brujo) (Puno -1897). Poeta de raigambre metafísica y de profunda manifestación espiritual, que por su sensibilidad artística desarrolló esquizofrenia. El poeta estuvo encerrado durante 50 años en el sanatorio mental Larco Herrera, sanatorio que compartió (según Versiones del Dr. Ricardo Arbulú Vargas) estadía junto a Martín Adán, Víctor Humareda, un grupo excepcional de artistas plásticos y músicos. La incomprensión se hizo bandera en una sociedad tan mal acostumbrada a las malas formas. Razón por la cual escribió sus poemas con el objetivo de expresar sus ideas que el futuro de la sociedad es vigorosa e incierta. También cuidar del pasado, aquellos acontecimientos dolorosos que es capaz de resistir a la acción destructiva de la unidad del Tiempo y el Espacio de una sociedad. Toda gran cultura es el resultado de la acción lenta y progresiva del espíritu de una raza o pueblo. Alberto mostajo dice que la unidad del Tiempo y el Espacio, es el espíritu, la suprema conciencia creadora y ordenatriz, causa de infinitas creaciones y dueña de maravillosa materia del gran dominio que no tiene principio ni fin. "Todo se crea y todo se destruye dentro de la unidad creadora e ilimitada del Tiempo y el Espacio".

\subsubsection{Actos del habla:}

Los 6 enunciados del poema constituyen un acto del habla. Desde de la perspectiva de la pragmática (actos de habla), el sujeto lírico cumple una acción al enunciar los versos, por lo cual consideramos al poema "Manicomio" como "acción". El autor a través del sujeto lírico cumple la acción de informar o afirmar. Entonces su intención es afirmar: "Un huracán de tristeza / azota la soledad de la estancia" y "Afuera, en ondas musicales, / trajina el lujo y la miseria”. Aquí el sujeto lírico afirma o en todo caso informa sobre la imagen que tiene del mundo, lo que observa y ocurre en una sociedad y lo que siente y piensa de ello. Esta afirmación trasciende la simple comunicación de sentimientos o emociones; más bien constituye una reflexión sobre la vida y la muerte, sobre la razón de la existencia humana.

A nivel del acto ilocutivo: El sujeto cumple la acción de "afirmar" aparte de comunicar el mensaje. Este acto comunicativo, desde luego, no es real, sino ficticio o fingido...

A nivel del acto perlocutivo: El efecto que produce el enunciado (o discurso) en el receptor. Los poemas generalmente conmueven la sensibilidad. Ahora bien, el poema "manicomio" puede ser recibido de distintas formas para los lectores. Sin embargo, para nosotras tomando en cuenta la intención comunicativa del sujeto lírico, podemos decir que el poema en mención produce efectos a nivel cognitivo y emocional. A nivel cognitivo, porque el receptor es informado de la visión que el sujeto lírico tiene del mundo. Esta visión básicamente es una reflexión de la vida, el mundo, la existencia humana. A nivel emocional, porque el receptor es ve "contagiado" de las emociones y sentimientos que el sujeto lírico expresa a través de los versos. En última instancia, cualquier lector sentirá algún gusto estético, y apreciará y valorará el poema que comentamos.

\section{CONCLUSIONES}

De acuerdo al estudio del análisis del poema "Manicomio" se concluye lo siguiente: 
En la dimensión textual, el poema cumple de manera general con las propiedades textuales (cohesión, coherencia y adecuación) por lo que tiene un sentido completo, el poema en general manifiesta un significado más connotativo, a diferencia de otros poemas.

En la dimensión semiótica, el poema expresa una angustia por la realidad que es ignorada por los integrantes de nuestra sociedad; describe como los individuos se preocupan por satisfacer necesidades vanas, cegándose e ignorando los acontecimientos lamentables que ocurren a nuestro alrededor.

En la dimensión enunciativa, en el poema existen dos voces; primeramente, está el sujeto empírico que es el autor del poema "Manicomio", quien crea un sujeto lirico para que mediante este sujeto exprese la angustia y la soledad que siente al ver la triste realidad que lo rodea.

En la dimensión pragmática, la creación de este poema es generado básicamente por la preocupación que siente el autor al ver la indiferencia que existe en la sociedad. Así mismo, la creación del poema estuvo influenciado por el encierro, durante una larga temporada en el manicomio, junto a otros autores conocidos.

\section{REFERENCIAS BIBLIOGRÁFICAS}

Basaglia, F. (1978). Razón, locura y sociedad (1ra edició). Mexico: Siglo Veintiuno Editores.

Basaglia, F. (2008). La condena de ser loco y pobre, alternativas al manicomio (1 ra edició). Buenos Aires: Topía Editorial.

Beaugrande, R., \& Dressler, W. (1997). Introducción a la lingüística del texto (1ra edició). Barcelona: Ariel.

Bevir, M. (2011). Lo inconsciente en la explicación social. Scielo Perú, 23(2), 223-262.

Cabello, J. (2015). Lectura crítica de la evidencia clínica (1era edici). Barcelona: Elsevier España.

Cabo, F., \& Gullón, G. (1998). Teoría del poema: la enunciación lírica (número 21). Amsterdam: Rodopi.

Calles, J. (1997). La modalización en el discurso poético. Universidad de Valencia.

Cardozo, V. (2016, octubre). El manicomio en el que vivimos. Montevideo portal.

Caruman, S., \& Quiroga, R. (1960). Teoría del Discurso. Chile.

Chomsky, N. (1999). Aspectos de la teoría de la sintaxis (1ra edició). España: Gedisa Editorial.

Correa, J. (2012). Semiótica (1era edici). Estado de Mexico: Red Tercer Milenio.

Filinich, M. (2011). Enunciación (2da edició). Buenos Aires: Editorial Universitaria de Buenos Aires.

Foucault, M. (2015). Historia de la locura en la época clásica I. (3era edici). Mexico: FCE Fondo de Cultura Económica. 
García, H. (2015, abril). Amilibia: «El mundo es un manicomio». La razón.

Gran diccionario de la lengua española. (2016). Gran diccionario de la lengua española. lauresse editorial, S.L.

Harris, M. (2004). Introducción a la antropología general (7ma edició). España: Alianza Editorial.

Heidegger, M. (2006). La fenomenología del espíritu de Hegel (2da edició). España: Alianza Editorial.

Hernández, R., Fernández, C., \& Baptista, P. (2006). Metodología de la investigación (Vol. 4). México.

Hernández, R., Fernández, C., \& Baptista, P. (2014). Metodología de la Investigación (Quinta Edi). Mexico.

Husserl, E. (1992). Invitación a la fenomenología (1 ra edició). Barcelona: Paidós.

Lada, U. (2001). La dimensión pragmática del signo literario. Estudios filológicos, (36), 61-70. https://doi.org/10.4067/S0071-17132001003600004

Lambert, C. (2006). Edmund Husserl: la idea de la fenomenología. Chile.

Molina, L. (2006). El Otoño del pingüino: análisis descriptivo de la traducción de los culturemas. Madrid: Universitat Jaume I.

Monje Álvarez, C. A. (2011). Metodología de la investigación cuantitativa y cualitativa. Guía didáctica. Universidad Surcolombiana, 1-217.

Niño, V. (2007). Fundamentos de semiótica y lingüística (5ta edició). Bogotá: Ecoe Ediciones.

Núñez, J. (2019). El poema XI de Alberto Mostajo a la luz del Análisis del Discurso. Revista Innova Educación, 1(2), 215-227. https://doi.org/10.35622/j.rie.2019.02.008

Penas, M., \& González, R. (2009). Estudios sobre el texto : nuevos enfoques y propuestas. Peter Lang.

Pico, I. (2009). La construcción simbólica de los derechos de la comunicación en la propuesta informativa de la asociación latinoamerica de educación radiofonica, Aler Ivonne. Facultad Latinoamericana de Ciencias Sociales.

Prieto, L. (2016). Franco Basaglia y el rol de "la locura" en la sociedad actual. Recuperado de https://www.laizquierdadiario.com/Franco-Basaglia-y-el-rol-de-la-locura-en-la-sociedadactual

Reyes, G. (1995). El abecé de la pragmática (9na edició). Madrid: Arco/Libros.

Sacristán, C. (2009). La locura se topa con el manicomio. Una historia por contar. Csielo, 45, 27.

Sartre, J. (2006). El existencialismo es un humanismo (1era edici). Mexico: UNAM, Dirección General de Publicaciones y Fomento Editorial.

Satriano, C., \& Moscoloni, N. (2000). Importancia del Análisis Textual como Herramienta para el Análisis del Discurso. Santiago de Chile. 
Tobón, R. (2004). Estrategias comunicativas en la educación: hacia un modelo semióticopedagógico (1ra edició). Medellín: Editorial Universidad de Antioquia.

Van Dijk, T. (1992). Estructuras y funciones del discurso: una introducción interdisciplinaria a la lingüística del texto y a los estudios del discurso (14ava edic). Barcelona: siglo xxi.

Van Dijk, T. (1998). Texto y contexto: semántica y pragmática del discurso (6ta edició). España: Ediciones Cátedra.

Vázquez, T. (2015). El mundo es un manicomio administrado por sus propios pacientes. $R T$.

Ybelisse, R. (2012). Hermeneutic like emergent qualitative paradigm in the oral health boarding (Vol. 13). 